\title{
O OLHAR INVISÍVEL: VISÕES E NARRATIVAS DE POPULARES EM SITUAÇÃO DE RUA E VULNERABILIDADE SOCIAL NOS TEMPOS DE PANDEMIA DA COVID-19 EM BRAGANÇA-PA
}

\author{
Erlan José Gatinho ${ }^{1}$ \\ João Plinio Ferreira de Quadros ${ }^{2}$ \\ Nivia Maria Vieira Costa ${ }^{3}$
}

\begin{abstract}
RESUMO
Devido a tantas mudanças abruptas que o mundo vivencia na atualidade, traz-se ao centro da cena, através desta pesquisa, alguns apontamentos reflexivos que se tornaram pertinentes como as desigualdades, as discriminações e os impactos sociais, além de transformações desencadeadas em tempos de pandemia da Covid-19. O objetivo geral da pesquisa está pautado em compreender como os grupos sociais em situação de rua e vulnerabilidade social da sociedade bragantina vivenciam a crise pandêmica. Como delineamento metodológico, se trata de uma pesquisa de abordagem qualitativa com os seguintes procedimentos: observação participante, rodas de conversa e análise interpretativa das narrativas orais. Entre os resultados obtidos permitiu-se conhecer parte destes grupos sociais que permeiam o locus da cidade, tal qual as múltiplas relações e ações que estes coletivos exercem, tornouse ainda viável entender dentre quais maneiras eles concebem o que é a pandemia, a quarentena e a crise manifestada em suas vivências e ressignificações. Epistemologicamente, a pesquisa baseia-se em conceitos de Velho (1973); Lefebvre (2011); Santos (2020); Bauman e Donskis (2016), com perspectivas conceituais e analíticas sobre: antropologia urbana, relações sociais, invisibilidades de grupo e reflexões críticas acerca da pandemia de Covid-19.
\end{abstract}

Palavras-chave: Antropologia urbana. Cidade. Vulnerabilidade Social. Solidariedade.

\begin{abstract}
Because so abrupt changes that the world is experiencing actually, through this research, some reflective notes that have become pertinent, such as inequalities, discrimination and social impacts, in addition to transformations triggered in times of pandemic, are brought to the center of the scene. of COVID-19. The general objective of the research it is based on understanding how social groups living on the streets and social vulnerability in bragantine society experience the pandemic crisis. As a methodological design, it is a qualitative research with the following procedures: participant observation, conversation circles and interpretative analysis of oral narratives. Among the results obtained, it was possible to know part of these social groups that permeate the locus of the city, as well as the multiple relations and actions that these collectives exercise, it became feasible to understand among which ways they conceive what the pandemic, quarantine and the crisis manifested in their experiences and resignificances. Epistemologically, the research is based on the concepts of Velho (1973); Lefebvre (2011); Santos (2020), Bauman and Donskis (2016), conceptual and analytical perspectives on: urban anthropology, social relations, group invisibilities and critical reflections about the COVID-19 pandemic.
\end{abstract}

Keywords: Urban anthropology; City; Social vulnerability; Solidarity.

\footnotetext{
${ }^{1}$ Mestre em Linguagens e Saberes na Amazônia, pelo Programa de Pós-graduação em Linguagens e Saberes na Amazônia - PPLSA/ UFPA-Campus Bragança. E-mail: erlan.winchester@ gmail.com.

${ }^{2}$ Mestrando no Programa de Pós-graduação em Linguagens e Saberes na Amazônia (PPLSA), pela Universidade Federal do Pará (UFPA) - Campus Bragança. E-mail: joaoambienta12017@gmail.com.

3 Pós-doutora em Educação, pela Universidade de Coimbra-Portugal. Professora do IFPA - Campus Bragança. E-mail: nivia.costa@ifpa.edu.br.
} 
Data de submissão: 04.08 .2020

Data de aprovação: 20.10 .2020

\section{INTRODUÇÃO}

As reflexões e conclusões apresentadas neste estudo são resultantes de investigações desenvolvidas pelos grupos de pesquisa "Laboratório de Estudos, Linguagens e Memórias" (LELIM/CNPq), e "Colaboratório de Interculturalidade, Inclusão de saberes e Inovação social" (COLINS/CNPq), ambos da Universidade Federal do Pará - UFPA, os quais têm contribuído para o desenvolvimento de reflexões e ações a respeito da diversidade de valores e práticas culturais na Amazônia, assim como promoção da inclusão de atores e saberes de grupos sociais no desenvolvimento local, através de ações e produtos colaborativos inclinados ao conceito do 'bom viver'.

Por intermédio de tantas mudanças abruptas que o mundo vivencia, traz-se ao centro de cena alguns apontamentos reflexivos que se tornaram pertinentes, dentre eles: desigualdades, discriminações e impactos sociais, transformações desencadeadas em tempos de Pandemia da Covid-19. Segundo o Boletim Epidemiológico do Ministério da Saúde do mês de janeiro de 2020, a Organização Mundial da Saúde (OMS), após reunião com especialistas, declarou Emergência de Saúde Pública de Importância Internacional em razão da disseminação do novo Coronavírus ou Covid-19. No Brasil, a partir de dados consolidados das secretarias estaduais de saúde, até o dia 28 de julho de 2020 foram registrados 88.634 óbitos e 2.484.649 diagnósticos de Covid-19, com 897 mortes confirmadas nas últimas 24 horas da referida data. O Pará ocupou o lugar de $5^{\circ}$ Estado com maior número de casos nesse contexto (SITE G1, 2020).

A sobrevivência humana se tornou eixo de discussão, portanto surgem contemplações pertinentes sobre o antagonismo entre solidariedade e individualismo na sociedade contemporânea. Atualmente há uma grande rede de solidariedade frente à pandemia da Covid19, e os fatos e as medidas tomadas nos indicam o nível de envolvimento do poder público e da sociedade, demonstram como as cidades se entrelaçam, se comportam e se transformam, ao mesmo tempo que deixam transparecer como as pessoas formam arranjos e redes, seja em um sistema micro, no envolvimento familiar e pessoas mais próximas, ou em sistemas macros, ou seja, mais amplos, envolvendo atividades institucionais e locais de trabalho.

O cenário descrito pelos veículos de comunicação, de forma geral, é o de que todos estão 'na mesma situação', pois o cingido conhecimento sobre o contágio do novo vírus revela que não há distinção em relação a cor, classe social e gênero. Todavia, a solidariedade que inclui alguns grupos sociais, geralmente está atrelada aos laços afetivos ou às conveniências sociais (vizinho, colega de trabalho, etc.), ou seja, não chegam a uma grande população vítima da invisibilidade nas cidades, como os moradores de rua, os dependentes químicos, os homoafetivos e demais segmentos de identidade de gênero.

De acordo com os técnicos do Centro de Referência Especializado de Assistência Social (CREAS) ${ }^{4}$, de Bragança-PA, os perfis das principais vítimas da Covid-19, certamente serão compostos, em sua maioria, pelos mais pobres. Assim, a população em situação de rua aparece como um dos grupos sociais mais vulneráveis. Consonante com Santos (2020), percebe-se que a população de rua "habita na cidade sem direito à cidade, já que, vivendo em espaços desurbanizados, não tem acesso às condições urbanas pressupostas pelo direito à cidade." (SANTOS, 2020, p.18).

\footnotetext{
${ }^{4}$ É um órgão estatal de abrangência municipal integrante do Sistema Único de Assistência Social e do Serviço de Proteção e Atendimento Especializado a Famílias e Indivíduos (PAEFI). Tem por objetivo ofertar ações de orientação, proteção e acompanhamento às famílias com um ou mais membros em situação de vulnerabilidade social, ou seja, foca nos territórios com maior vulnerabilidade e faz com que todos tenham acesso aos direitos socioassistenciais.
} 
Na cidade de Bragança a estatística de moradores em situação de rua é considerada volátil, atualmente estão cadastrados 120 moradores de rua, o quantitativo condiz "justamente em virtude dessas pessoas terem a liberdade de transitarem de forma livre, pois não possuem residência, trabalho e, na maioria das vezes, são rejeitados pelas famílias", de acordo com relato de um pedagogo do CREAS. Ele ainda afirmou que a maioria desses moradores de rua são de outros municípios paraenses e alguns de outros Estados.

A pobreza e desprovimento fazem parte da realidade social de um grande contingente de brasileiros, que incluem as pessoas em situação de rua. E essas pessoas estão associadas a outras vulnerabilidades, transformando-se em um grupo completamente suscetível ao vírus, pois muitos são idosos, alguns já estão doentes e há grande dificuldade em colocá-los em quarentena ou estabelecer o distanciamento social, pois vivem em grupos, circulam por muitos territórios da cidade, são transeuntes todo o tempo. Ademais, a pandemia acentuou e deu visibilidade há uma série de problemas sociais estruturais causados pelo atual sistema capitalista, pelo colonialismo e pelo patriarcado, dentre eles a divisão de classes, a devastação ambiental, a exclusão social, a discriminação e a extrema pobreza, entre tantos outros (SANTOS, 2020).

Por tais aspectos mencionados anteriormente, forma-se o seguinte questionamento: "Como será a quarentena de quem não tem casa?", esta indagação foi realizada por Boaventura Santos, na obra A Cruel Pedagogia do Vírus (2020). Destarte, o autor lança um amplo panorama sociológico no sentido de desvelar aspectos não visíveis dessa pandemia, pelo menos do ponto de vista social, mostrando também que ela é reflexo de todo um processo histórico, cultural e político anterior, referente ao modo de vida da humanidade sob os efeitos do capitalismo, bem como do aprofundamento do neoliberalismo enquanto modelo econômico (COELHO \& FRANZ, 2020).

De acordo com as constatações de Santos (2020), surgiu a questão-problema do presente estudo: como o grupo social dos moradores de rua vivencia a crise pandêmica da Covid-19 na cidade de Bragança-PA? De forma geral, objetivou-se compreender como os grupos em situação de rua e vulnerabilidade social da sociedade bragantina vivenciam a crise pandêmica. Especificamente, os objetivos foram: averiguar as concepções dos agentes sociais sobre si em tempos da pandemia; identificar através de narrativas dos interlocutores qual ou quais ações socioassistencialistas lhes foram ofertadas em meio à crise pandemiológica; e analisar possíveis estratégias de adaptações sociais desses interlocutores e suas narrativas em relação ao contex to que vivenciam.

Através de investigações sobre pesquisas desenvolvidas sobre o assunto, verificou-se que a maioria delas tem um enfoque sobre a cidade em um plano macroestrutural, isto é, das instituições e da estrutura que compõem a cidade, assim os indivíduos que a habitam são interpretados como agentes passivos desse cenário, como se fossem desprovidos de atividades, sociabilidades e ações individuais.

Tendo em vista essas circunstâncias no meio urbano, ressaltam-se as mudanças ocorridas sob as perspectivas antropológicas, com novas áreas de investigação abertas. Mais do que nunca, os povos ditos 'primitivos' deixaram de ser o único objeto da Antropologia e fica cada vez mais claro o entendimento de que o 'outro' não precisa, necessariamente, estar distante do pesquisador. Nesse sentido, o sujeito urbano passa então a ser visto como um indivíduo dotado de diversidade cultural.

Conforme Park (1921 apud VELHO, 1973, p. 28) afirmou, “o homem civilizado é um objeto de investigação igualmente interessante, e ao mesmo tempo sua vida é mais aberta à observação e ao estudo". Pensando nesse sujeito, a cidade se tornou o lócus das pesquisas antropológicas dedicadas aos grupos urbanos, que concentra e multiplica toda a complexidade existente entre as sociedades modernas. Surge desse contexto uma nova área da Antropologia, a qual ficou conhecida como "Antropologia Urbana" (VELHO, 1973). 
Segundo Lakatos (2010), apesar de tratar de objetos totalmente diferentes, a Antropologia Urbana também priorizou escolher o mesmo método de pesquisa utilizado pelos antropólogos que estudam sociedades 'simples': a observação participante e a etnografia. Metodologicamente, esse estudo se baseou na pesquisa de abordagem qualitativa e delineouse por procedimentos como: observação participante, rodas de conversa e análise interpretativa das narrativas orais.

O início da pesquisa aconteceu mediante o contato com a coordenação geral do abrigo - servidores do CREAS (Centro de Referência Especializado de Assistência Social), para explicar a intenção do trabalho a ser desenvolvido e solicitar a autorização. Foi-lhes entregue uma carta, com a descrição dos objetivos do estudo e a solicitação de colaboração da instituição. Após todos os trâmites legais aconteceu a pesquisa de campo. A observação participante propiciou a interação do pesquisador com a situação pesquisada, uma vez que "a observação é chamada de participante porque parte do princípio de que o pesquisador tem sempre um grau de intenção com a situação estudada, afetando-a e sendo por ela afetado" (ANDRÉ, 2007, p. 28).

Como lócus da pesquisa foi escolhido o abrigo para moradores em situação de rua, localizado na Escola Municipal Prof ${ }^{a}$ Júlia Quadros Peinado, sobretudo, pelo fato de ter sido o único abrigo no Município de Bragança-PA que atendeu à demanda. Para a obtenção dos depoimentos orais foi utilizada a técnica roda de conversa. De acordo com Gatti (2005), essa técnica permite compreender processos de "construção da realidade, por determinados grupos sociais, comportamentos e atitudes, representações, percepções, crenças, hábitos, valores, restrições e preconceitos" (GATTI, 2005, p.11). Utilizou-se o gravador de voz para captar as falas dos agentes sociais e, posteriormente, foi feita a transcrição dessas falas.

Participaram desse estudo 03 (três) moradores em situação de rua que vivenciam a experiência do abrigo, justifica-se esse quantitativo em virtude da recusa da grande maioria em participar de entrevistas, além destes interlocutores, participaram os 02 (dois) coordenadores do projeto (01 Pedagogo e 01 Assistente Social). A pesquisa foi desenvolvida nos meses de junho e julho de 2020.

Antes da apresentação e análise das narrativas coletadas, na segunda e na terceira sessões, na primeira sessão há aportes teóricos referenciais e considerações sobre Antropologia Urbana e grupos em vulnerabilidade social.

\section{A CIDADE INVISÍVEL: ENTRE CONFLITOS E RESSIGNIFICAÇÕES DE GRUPOS VULNERÁVEIS EM TEMPOS DE PANDEMIA}

No Brasil, a década de 70 foi o período quando surgiram os primeiros estudos da Antropologia Urbana. Magnani (2002) aponta que a Antropologia surge em seus primórdios como uma ciência que busca compreender sociedades simples, isto é, colônias, grupos indígenas e rurais, minorias sociais e etc., entretanto, as transformações históricas e sociais que atingiram essas sociedades transformaram colônias em Estados-nação, colocando indígenas e as populações rurais em contato com o chamado 'progresso urbano', isto é, minorias sociais expostas à cultura dominante.

Lefebvre (2011) sintetiza a compreensão de cidade em sua formação desde o próprio conceito até as novas concepções deste termo, pode-se compreender que inicialmente as cidades eram um local onde um conjunto de tribos e povos se encontravam e viviam, hoje esta definição não se difere em muito, pelo fato que nas cidades atuais os grupos sociais que permeiam seu interior são inúmeros e dos mais variados segmentos ideológicos e socioculturais, por outro lado, na relação social contemporânea nas urbes as variações de grupos e tribos urbanas são mais complexas e com novas características, as quais as diferem das cidades arcaicas. 
Outro fator importante sob a constituição dos estudos urbanos é o advento das revoluções industriais e do próprio capitalismo, por isso a contemporaneidade apresenta diversas transformações sobretudo nas cidades. Contudo, reconhece-se que relacionar a cidade com as características basilares da modernidade não quer dizer que estas não existiam na época pré-industrial e pré-capitalista, entretanto, tinham um caráter diferente do que têm hoje. (MAGNANI, 2002).

Segundo Bauman e Donskis (2016, p. 26) "[...] a cultura consumista transforma cada loja e agência de serviços numa farmácia fornecedora de tranquilizantes e anestésicos: neste caso, drogas destinadas a mitigar ou aplacar não as dores físicas, mas a dor moral”. Nesta linha, as cidades são palcos de uma realidade complexa e múltipla em todos os sentidos, dentre eles, culturais e sociais, e estão em constante transformação. Esta multiplicidade pode se expressar nos traços pessoais, nas ocupações, na vida cultural e nas ideias dos habitantes da comunidade urbana, podendo resultar em separações espaciais dos indivíduos de acordo com essas características (VELHO, 2003).

Mendoza (2000) parte da premissa de que oportunizar voz a esses moradores se torna fundamental para mostrar componentes da cidade que não são visíveis em grande parte dos estudos acadêmicos, isto é, "trata-se de conhecer como esses grupos urbanos organizam, classificam, representam, atuam e constroem o seu espaço e modo de vida dentro de um sistema urbano." (MENDOZA, 2000, p. 191).

Convém destacar estudos do teórico Lefebvre (2011), o autor traça um esquema linear e apresenta a formação inicial da cidade, a transição do campo para ela e, ao final do eixo, a absorção dos campos pelas urbes. Entre esses eixos de deslocamento se encontra o ponto crítico, o que mostra que há uma descontinuidade presente no mesmo, e há inúmeros pontos críticos, dentre os mais agravantes está o momento em que ocorrem as expansões das cidades. As cidades invadem os campos e os subúrbios, e outras áreas periféricas também se manifestam, e é ao redor desse ponto crítico que a cidade apresenta sua adversidade (LEFEBVRE, 2011). Nesses parâmetros os pontos críticos são todas as causas e também as consequências que ocorrem no meio urbano, de forma espontânea ou imposta, mas que cria uma desestruturação na ordem social, como a violência, a fome, a discriminação, dentre outros.

Sobre a relação da cidade e os impactos sociais em tempos de pandemia, Santos (2020) afirma que a pandemia de Covid-19 nada mais é do que o reflexo de uma crise humanitária mais abrangente que assola a sociedade a nível global há tempos por meio de causas naturais, socioeconômicos, financeiras, políticas, entre outras, tendo como ênfase a discussão desse estudo sobre os aspectos urbanocêntricos.

A cidade engloba inúmeros meios de análise das consequências dessas aflições mundiais, como conhecer os grupos sociais que permeiam esse lócus, tal qual as múltiplas relações e ações que eles exercem, o que torna viável entender dentre quais maneiras estes grupos concebem o que é a pandemia, a quarentena e a crise manifestada em suas vivências e com suas significâncias.

É fato que as crises já afetam a humanidade por um longo período, desde a compreensão destas, sendo manifestadas em formas e intensidades diferenciadas, como seus meios de proliferação e causas. Muitas doenças afligem grande parte da população mundial, com destaque para aquelas em área de risco ou em critério de pobreza e fome extrema, para as quais não há recursos de saúde, assistências e saneamento básico. O que se deve questionar é o fato de as situações epidemiológicas ou pandemiológica só serem alarmadas mundialmente ao atingirem países mais ricos, fato evidenciado no excerto a seguir:

As epidemias de que o novo Coronavírus é a mais recente manifestação só se transformam em problemas globais graves quando as populações dos países mais ricos do Norte global são atingidas. Foi isso que sucedeu com a epidemia da 
SIDA/AIDS. Em 2016, a malária matou 405 mil pessoas, a esmagadora maioria em África, e isso não foi notícia. (SANTOS, 2020. p. 26).

A partir do pensamento anterior destacado, torna-se perceptível que os governantes dos países ricos ou do sistema de governo capitalista, como cita Santos (2020), são quem proporcionam a maior parte da propagação dessas crises, possibilitam uma 'normalidade' dessas doenças à população mundial. Essa habitual absorção de banalidade das mortes, misérias e tragédias que as populações mais vulneráveis sofrem ao longo dos tempos, faz com que visibilize esses grupos sociais também, e cria-se um tipo de 'darwinismo social' em que os populares, considerados apenas como não-consumistas, não geradores de emprego e renda e invisíveis aos olhos das classes mais favorecidas economicamente e dominantes, são associados a uma limpeza social e suas mortes são naturalizadas, ocultadas e sem valor para a sociedade de um modo geral.

Santos (2020) afirma que as populações nas cidades de países em situação de risco e vulnerabilidade socioeconômica são as que mais são atingidas diretamente, tanto pela pandemia quanto por suas demais consequências na estrutura sociocultural. Especificamente nas cidades onde os indivíduos se relacionam com outros e desenvolvem uma cadeia social de relações, interdependências e mutualidade, gera-se também fonte de renda, cultura e demais produções para a cidade como um todo, sendo assim, tão necessários quanto os governantes e/ou a classe dominante.

Nessa linha de pensamento temos a cidade estetizada apenas pelas suas arquiteturas, suas áreas de lazer, entretenimento, garantia de emprego, que durante muitos séculos movimentou o então chamado êxodo rural. E pensando no contexto da Covid-19, cada vez mais a sua outra face é exposta, isto é, uma cidade invisibilizada pela mídia em alguns casos, órgãos governamentais ou a classe dominante no sistema capitalista, os quais tentam ocultar e ignorar essa outra parte presente no cotidiano e intrinsecamente em todas as dimensões que compõem a urbe. Nesse ínterim os moradores de rua aparecem e revelam muitos aspectos importantes das dificuldades com a pandemia e com as ações governamentais, dentre outros aspectos antes e durante a instauração da doença.

\section{REDESCOBRINDO BRAGANÇA SOB AS NARRATIVAS E VISÕES DE MORADORES EM SITUAÇÃO DE RUA EM TEMPOS DE PANDEMIA}

A partir dos resultados e discussões referentes às narrativas e concepções dos interlocutores deste estudo acerca de suas possíveis visões sobre si próprios e em relação às ações assistencialistas, que possivelmente lhes foram ofertadas ou assistidas no período da pandemia de Covid-19, averiguou-se quais destas foram efetivadas com os grupos em vulnerabilidade em meio à crise. Ao evidenciar o nome real dos interlocutores no presente estudo, após autorização, buscou-se, em uma perspectiva decolonial, definir que estes não são apenas sujeitos da pesquisa, mas agentes sociais que a constroem mediante suas narrativas junto aos autores da mesma.

\subsection{NA ESTRADA ENTRE BECOS E QUEBRADAS: PERCURSOS TRAÇADOS}

De acordo com as narrações dos agentes sociais participantes da pesquisa, suas realidades enquanto moradores de rua foram ocasionadas por diferentes fatores nos âmbitos familiar, social, cultural e demais relações que lidaram, ações estas que foram influenciados a praticar no decorrer de suas vivências. Com esse entendimento, foi-lhes questionado a respeito de como se identificariam, propondo evidenciar seus olhares sobre si mesmos e não 
imagens construídas deles por outras pessoas. Assim, seguem os relatos dos três primeiros interlocutores ${ }^{5}$ :

Primeiro relato:

Eu sou Robson da Silva, eu tenho 32 anos, e não sou daqui né, o bairro que morava em Belém era o Bem

gui. Eu praticamente sou de Belém né. Durante esse tempo fui criado com vó. Então, eu fui, a minha avó mora com a minha mãe em Belém e, desde que eu fui deixado da minha vó, eu fui pescador né. Então, todo esse tempo desse período que cheguei aqui eu nunca mais fui pescar.

Segundo relato:

Meu nome é Miguel Baldez da Silva, eu tenho 42 anos né, eu, não sou daqui do estado do Pará, meu pai era, eu vim de Mato Grosso né, ai no caso vim pra casa da misericórdia, aí saí, vim pra rua, [...] até uns dez anos atrás eu tive uma vida até bem estabelecida né, sempre tive, sempre trabalhei, ai aconteceu uma separação com a mãe da minha filha, aí eu debandei da cabeça, aconteceu muita coisa errada na minha vida e só foi decadência, então pra evitar ficar perto deles e eu acabar fazendo uma besteira comigo mesmo, fazendo uma besteira pra mim mesmo, então resolvi sair no mundo pra ver qual que era, o que era mais diferente, acabei vendo, não digo que peguei gosto, mas, vamos dizer assim fui sobrevivendo e até como estou até hoje.

Terceiro relato:

Então, eu me chamo Flavio Augusto Lima Peralta, bem no início como eu posso dizer, como o próprio assistente social Nill falou eи não sou um morador de rua eu me encontro em uma situação de rua, eu vim pra cá pra Bragança pra recomeçar minha vida com minha ex companheira, e devido alguns problemas em nossa vida conjugal e a gente acabou se separando, e como eu estou com a minha irmã na justiça devido ao falecimento da nossa mãe, me foi tirado o direito de residir no meu próprio apartamento por questões de dependências químicas, então foi quando eu vim para cá, para Bragança.

Ao averiguar as inferências dos interlocutores, percebeu-se que há particularidades e semelhanças presentes em suas falas, dentre elas: problemas familiares, conjugais e financeiros. $\mathrm{O}$ aspecto que merece atenção é o fato da não identificação desses agentes sociais enquanto moradores de rua, termos comumente usados para definir aquelas pessoas, precisamente 'em situação de rua' - hoje os termos mais usados conceitualmente. Ainda assim, nas falas observadas não foram utilizados ambos conceitos citados anteriormente, e no lugar deles os interlocutores se identificaram apenas considerando suas relações familiares e profissionais, tais como: pescador, trabalhador informal, pai de família e estudante.

Bauman e Donskis (2016, p.21) afirmam que "[...]destituir os seres humanos dos seus rostos e da sua individualidade não é uma forma de mal menos importante do que reduzir a sua dignidade ou procurar ameaças sobretudo entre aqueles que migraram ou que têm crenças religiosas diferentes.", então após os questionamentos sobre suas imagens em uma relação intimista, colocou-se em voga a importância de se conhecer como percebiam o olhar da sociedade sobre eles, diante da situação de rua que vivenciam, assim foi questionado sobre a visão que a população pudesse ter antes e durante o período da pandemia da Covid-19. O interlocutor Flávio Peralta afirmou que

Olha o que eu acho é o seguinte, as pessoas aqui, as poucas que eu conheci aqui de Bragança, que estavam lá no ginásio, me falaram assim...de solidariedade os residentes daqui de Bragança, me falaram que são pessoas boas, que gostam de

\footnotetext{
${ }^{5}$ Silva, Robson da; Silva, Miguel Baldez da; Peralta, Flávio Augusto Lima. Roda de conversa sobre situações da pandemia para pessoas em situação de rua. [Entrevista cedida a] Erlan José Gatinho e João Plínio Ferreira de Quadros. Jun. 2020.
} 
ajudar, principalmente aquelas pessoas que estão em situação de rua, que estão no quadro de situação de rua, né, até então eu não tive a oportunidade de ficar como eles falam 'mangando' na rua, mangando para conseguir um café, quando eu cheguei eu fiquei 3 dias com a minha companheira passada e de lá eu fui logo para o abrigo emergencial, a gente vê que as pessoas realmente daqui elas são pessoas que gostam de ajudar, são pessoas cordiais. (FLAVIO PERALTA, 2020)

O relato foi prosseguido pela fala de Miguel, ator social em conflito infere sobre o preconceito que sente por estar em situação de rua e ser invisibilizado pela sociedade, como segue:

\begin{abstract}
Na realidade o preconceito é geral, em tudo quanto é lugar, ninguém vê o morador de rua como alguém, mas sim aquele que tá incomodando, e com isso você tem que 'rebolar de um lado para o outro', não adianta você dizer que é morador de rua que todo tempo você vai tá bem, na realidade têm aqueles que lhe olham com carinho né, com dó, e tem aqueles que lhe olham com nojo, e é verdade mesmo não é mentira, as pessoas olha pra você como se não valessem nada, como se não fosse alguém, essa é a verdade. Infelizmente o ser humano é julgado pelo que ele tem,o morador de rua como ele não tem nada, ele não é ninguém, à vista de muitos e geralmente dos que mais têm, os que menos tem são aqueles que mais ajudam, os que mais tem eles fazem é evitar você chegar perto, acham que você é um lixo, uma doença, sem esquecer que um dia um parente deles ou alguém pode acontecer coisa pior ainda, e quem é que vai querer ajudar eles? Eles vão querer ajudar? Sendo que não ajudaram um estranho vão querer ajudar um parente? Eu tenho assim uma parte de preconceito com algumas pessoas que tem condição, do mesmo jeito que eles têm preconceito comigo eu também tenho com eles, na realidade, nem sei a palavra (MIGUEL BALDEZ, 2020).
\end{abstract}

De acordo com Bauman e Donskis (2016), eram felizes os tempos em que havia formas evidentes do mal, hoje já não sabemos quais são, nem onde estão. Mas se feita uma lista dos novos bloqueios mentais, ela incluiria nosso esquecimento deliberado do Outro, a nossa recusa em reconhecer seres humanos de vários tipos e, ao mesmo tempo que não ouvimos o que ele diz ao nosso lado, fabricamos "amigos virtuais" distantes, de outras realidades semióticas. Grigory Kanovich, escritor lituano-israelita, em seu romance $O$ Feitiço do Diabo (2009), descreve a perda de memória e da sensibilidade através da personificação do Diabo, como aspectos inevitáveis do modo como esse personagem afeta a humanidade durante revoluções sociais, desastres, guerras e calamidades, trata-se de uma importante construção figurativa do caos na atualidade. (BAUMAN \& DONSKIS, 2013).

\title{
2.2 UMA NOVA QUARENTENA: POR PERCALÇOS, CONFLITOS E ENTRE PEDRAS NO CAMINHO
}

Partindo das premissas anteriores, mediante as narrativas dos atores sociais, foi-lhes questionado se passavam por dificuldades por estarem em situação de rua em meio ao contexto da pandemia e, se sim, quais seriam. O interlocutor Robson afirmou:

Então, hoje em dia isso para mim me dói muito, cara, porque vejo assim as pessoas que não tem nada, e hoje em dia para mim, tá vivendo no meio dessa sociedade, e por incrível que pareça, mas é... se torna assim imprevisível né, vamos dizer assim. Então,[...] como nós moramos na rua é uma coisa que eu vejo que é muito triste, eu vejo essas coisas assim cara, aquilo que me comove muito cara, seja um menino passando mal de fome, situações que não tem um teto para morar, eu fico um cara encabulado com isso (ROBSON, 2020). 
O morador de rua reafirma sua condição, a define como sendo imprevisível e apresenta uma percepção que outrora não tinha antes do contexto de pandemia de Covid-19, uma vez que "[...] quando o surto ocorre, a vulnerabilidade aumenta, porque estão mais expostos à propagação do vírus [...]" (SANTOS 2020, p. 27). Já o interlocutor Miguel afirma que

Foi um pouco né, porque tem pessoas que tem bondade no coração, eu passei em várias outras cidades e não vi isso, mas aqui, graças a Deus, as pessoas são de verdade mesmo, são boas de coração, algumas né, não são todas, na realidade não pode colocar tudo num pacote só. (MIGUEL BALDEZ, 2020).

O interlocutor destacou a solidariedade de alguns nesse contexto. Buscando-se um terceiro olhar, fez-se a mesma interrogação a Flávio Peralta, que ressaltou que estar em um mesmo lugar limitado de espaço lhe causou estranheza, mas manteve a mente equilibrada, como segue,

É, para mim foi, a gente ficava num espaço bem limitado não sei se vocês tiveram a oportunidade de conhecer o ginásio antes, mas o ginásio ele é grande, tinha um espaço ali, mas mesmo aquele espaço tinha um momento que incomodava, porque a gente estava ali naquela rotina diária e o pessoal querendo ou não aqui fora eles estavam vivendo, e pra mim, falando pra mim mesmo foi bem sufocante, mas estava a todo tempo tentando me manter com a mente aberta, recebendo as orientações dos coordenadores, procurando fazer alguma coisa para distrair a cabeça. (FLÁVIO PERALTA, 2020).

As mudanças pandêmicas afetam a sociedade como um todo, em divergentes aspectos, tanto sociais quanto financeiros e emocionais (SANTOS, 2020), dar voz a quem não é visto por muitos é escutar o mundo em suas multivozes invisibilizadas. As narrativas manifestadas desses populares se tornam parte fundamental para compreender as múltiplas visões que se reformulam no meio social em contexto de pandemia, sobretudo os olhares e crenças dos populares que em muitos casos são ignorados no meio social, assim, não somente se deve analisar os pensamentos esperançosos que estes possam ter, mas seus medos e demais sensações manifestadas em ações que demonstram em seus discursos.

Ao enunciar suas visões, os atores sociais possibilitaram a compreensão, por sua vez, a respeito do serviço que lhes foi ofertado por meio do abrigo emergencial, a próxima questão proposta. Foi-lhes questionado como foi para eles esse tempo de permanência em que ficaram assistidos no abrigo emergencial. Todos responderam que foram muito bem tratados e tiveram dignidade no acesso aos serviços públicos, conforme segue:

Praticamente, foi um abrigo bacana, legal, a gente tinha um bom contato com o pessoal lá de dentro, a gente conversava com as meninas por lá, com os rapazes também. Então, aquilo para mim foi totalmente demais, foi super bacana, ótimo, não teve atrito nenhum e todo mundo que estava lá acho que estão bem né, não tem nenhum doente. Então, eu quero que eles fiquem bem de saúde e trabalhem para se manter vivo, né. Eles lá foram umas pessoas bacana com a gente, o que eles pediam a gente fazia a gente prendemos muita coisa com eles também, tanto eles como nós, e desejo muitas felicidades para eles, para família deles todos. (ROBSON, 2020).

Um dos agentes sociais relatou sua dificuldade em conviver com tantas pessoas próximas, mas disse que se sentiu respeitado e valorizado por todos, conforme segue:

Eu não tenho do que reclamar, na realidade todos eles foram bem humildes com a gente, sempre deram atenção até que demais (risos), eu não sei tratar com esse tipo de pessoas à minha volta o tempo todo, não tenho esse costume, e para mim foi muito, muito bom, eu mesmo não tenho o costume de está com pessoas do meu lado 
direto, eu até estranhei o modo que eles tratavam a gente com eles lá, mas foi legal. Quando eu fui pra lá eu não estava mais na casa de misericórdia, não, não, eu tinha saído fazia uns dois meses, fazia um tempo que já estava na rua já, e ficava lá na praça de eventos. As pessoas fizeram mutirão pra doar os alimentos né, as coisa para nós lá, e não tenho do que reclamar, foi ótimo, bom mesmo, eles sempre nos respeitaram e exigindo nosso respeito por eles, eles faziam palestras lá, tinha, eu não sou muito fã de esportes mas ficava acompanhando os jogo deles lá, acompanhava olhando. (MIGUEL BALDEZ. 2020).

Em um dos relatos, um agente social nos informou que permaneceu nos serviços de assistência somente até receber o auxílio emergencial e relatou o quanto "se sentiu bem" no local,

\begin{abstract}
Sobre o abrigo assim, eu não tenho nada do que reclamar do serviço deles, tanto no abrigo quanto no Centro Pop, que é outro serviço né, e cheguei a fazer parte do Centro Pop e do Pop rua, mas como eu conseguir o auxílio eu sai do serviço, mas o serviço ajudou bastante, para muitas pessoas, mas depende de pessoa para pessoa, para outras eu vi que não, as pessoas queriam resultados imediatos, mas eи me senti bem. (FLAVIO PERALTA. 2020).
\end{abstract}

Santos (2020) aponta para o questionamento das medidas de segurança apresentadas pelos órgãos globais e Estados-nação sobre a prevenção e cuidados referentes à pandemia da Covid-19, assim ele discute sobre o sentido etimológico do termo 'pandemia', descrevendo que significa 'todo povo' e, nesse pensamento de um modo coletivo de enfretamento dessa atribulação, algo que parece ser contraditório é o fato de que para ser solidário, deve-se evitar o contato, isolar-se, tal qual infere o teórico que a " [...] melhor maneira de sermos solidários uns com os outros é isolarmo-nos uns dos outros e nem sequer nos tocarmos" (SANTOS, 2020, p. 07).

Através das narrativas de todos os interlocutores da presente pesquisa foi evidenciado que bem mais do que os serviços e recursos ofertados no período em que estiveram no abrigo emergencial, foram mais significativos os atos de solidariedade e o contato que tiveram com os servidores e prestadores de assistência no local. Contudo, embora estivessem em isolamento, as proximidades com as demais pessoas e a forma como foram auxiliados se configuraram como cruciais para viverem o momento enquanto moradores em situação de rua.

\title{
2.3 A ESTRADA ATÉ AQUI: TRILHANDO NOVOS RUMOS EM VIAS INCERTAS
}

Com a análise de visões e narrativas dos agentes sociais da pesquisa enquanto grupo social e a crise que assola, reconhecendo possíveis estratégias de adaptações sociais para o período pós-pandêmico, interrogou-se posteriormente se eles pensam em continuar na cidade de Bragança ou voltar à cidade natal. A pergunta foi dirigida inicialmente a Robson, que descreveu o quanto gostou da cidade, mas não respondeu claramente sua pretensão de permanência.

A população é bacana, ótimos, não tenho o que falar, a cidade também é bacana. Essas pessoas que são é... praticamente são umas coisas bem imprevisíveis né, eles são umas coisas que tudo que tem ao redor da gente tem que preservar e essas pessoas que são ótimo mesmo, bacana, legal tem que falar, a cidade também é boa e dá para se viver. (ROBSON,2020).

Outrossim, quando indagados os demais agentes sociais, por sua vez, tiveram respostas opostas, um pretende permanecer e outro voltar para sua terra natal, Belém-PA. 
Merece destaque que ambos fizeram referência a voltar a ter uma vida estável, com um trabalho para seu próprio sustento:

\begin{abstract}
Se sair essa vacina não vai sair por agora, então a vida tem que continuar do mesmo jeito, eu não vou te mentir não, depois que eu gostei dessa cidade aqui eu não pretendo mais sair, mas não quer dizer que eu vá ficar, querer é uma coisa, poder é outra, mas se eu conseguir uma condição financeira minha trabalhando, uma estadia minha morando numa casa nem que seja de aluguel, mas, que seja algo que eu possa dizer assim isso aqui é meu, porque eu pretendo voltar a ter a vida que eu tive antes, voltar a ter o nome de trabalhador, não o nome de vagabundo de rua. Eu não posso dizer que eu gosto de aqui por aqui, eu gosto pelo geral, aqui é um lugar bom, é receptivo, basta você saber viver, sem precisar ter muita coisa, isso é algo que me agradou aqui. (MIGUEL BALDEZ, 2020).
\end{abstract}

\begin{abstract}
Bem o espaço em si né, porque fui nascido e crescido ainda em um fluxo de drogadição muito alto, e com um passado muito obscuro ainda, então penso na minha cabeça que antes de voltar para lá e voltar e começar tudo novo. (...)Então isso é uma pergunta bem interessante porque eu penso em voltar pra Belém sim, como meus amigos falam, Flávio se você vier aqui você vai ter onde ficar, tenho muitos amigos, a minha família, irmão, como eu disse não me deu suporte nenhum, sempre me repudiaram pela questão da dependência química, então a minha estadia aqui em Bragança é também para recarregar as pilhas as minhas energias, mas eu ainda não tive a oportunidade de conhecer Bragança por completo, me falaram que aqui é um lugar bem tranquilo para se viver, montar um bom negócio, mas a priori a minha vontade é de voltar para Belém, para a Cidade Nova. (FLAVIO PERALTA, 2020).
\end{abstract}

Lefebvre (2011), ao falar sobre o direito à cidade, discute sobre as distintas formas de necessidade que se constroem e desenvolvem os populares, afirmando que, até então, tem-se evidenciado necessidades básicas ou afetivas da camada dita mais favorecida ou mais rica, enquanto grupos sociais invisibilizados são segregados, com seus anseios ocultados (LEFEBVRE, 2011). Para Bauman e Donskis (2016, p.19) “[...] o mal não está confinado à guerra ou a ideologias totalitárias. Hoje ele revela-se com mais frequência quando deixamos de reagir ao sofrimento de outra pessoa, quando nos recusamos a compreender os outros, quando somos insensíveis e evitamos o olhar ético silencioso".

\title{
3 CONSIDERAÇÕES FINAIS
}

É determinante que a pandemia da Covid-19 é o reflexo de uma crise humanitária mais abrangente que atinge a humanidade a nível global há tempos, seja por meio de causas naturais, socioeconômicas, financeiras ou políticas. E sendo ênfase deste estudo a discussão sobre os aspectos urbanocêntricos, pode-se afirmar que a cidade nos permitiu conhecer parte dos grupos sociais evidenciados que permeiam esse lócus, tal qual as múltiplas relações e ações que eles exercem. E tornou-se viável entender como concebem o que é a pandemia, a quarentena e a crise manifestadas em suas vivências e ressignificações.

Pode-se concluir que os interlocutores desse estudo já vivenciavam uma quarentena, antes mesmo da Covid-19, visto que a situação de rua já direcionava para um isolamento social involuntário, ou seja, os múltiplos olhares invisíveis das cidades, embora sejam considerados atores sociais providos de direitos, muitos destes são lhes negado ou omitidos. A mídia, órgãos governamentais e a configuração da classe dominante capitalista tentam ocultar e ignorar essa outra parte presente no cotidiano e, intrinsecamente, em todas as dimensões que compõem a urbe.

A habitual absorção de banalidade das mortes, misérias e tragédias que as populações mais vulneráveis vêm sofrendo ao longo dos tempos faz com que se invisibilizem estes grupos sociais. Todavia, as vivências no abrigo emergencial permitiram soluções práticas para 
as pessoas em situação de rua, que vão além da aquisição de objetos materiais (roupas, calçados, colchões etc.), são as relações que se construíram e foram desenvolvidas por meio de atitudes solidárias, fraternas, de equidade e alteridade, permitiram assim uma dialética social, na qual através dos olhares e reconhecimento dos outros, suas vozes, por muito silenciadas, foram ouvidas e suas visões valorizadas e compreendidas, sobretudo, respeitadas.

\section{REFERÊNCIAS}

ANDRÉ, Marli Eliza D. A. de. Etnografia da prática escolar. 13. ed. Campinas, São Paulo: Papirus, 2007.

BAUMAN, Zygmunt; DONSKIS, Leonidas. Cegueira Moral - a perda da sensibilidade na modernidade líquida. Lisboa, Portugal. Relógio D’Água Editores, 2016.

COELHO. Gabriel Bandeira. FRANZ. Alice Hubner. A cruel pedagogia do vírus. Ciências Sociais Unisinos: revista do Programa de Pós-Graduação em Ciências Sociais da Universidade do Vale do Rio dos Sinos (Unisinos), São Leopoldo, n. 1, jan/abr. 2020. Disponível em: http://revistas.unisinos.br/index.php/ciencias_sociais/article/view/csu.2020.56.1.10/60747777. Acesso em: 01 abr 2020.

GATTI, Bernadete Angelina. Grupo focal na pesquisa em ciências sociais e humanas. Brasília: Liber Livros, 2005.

LAKATOS, Eva Maria. Fundamentos da metodologia científica. - 7. Ed. - São Paulo: Atlas, 2010.

KANOVICH, Grigory. O Feitiço do Diabo. Noir Press, Reino Unido, 2009.

LEFEBVRE, Henri. O direito à cidadania. Trad. Rubens E. Frias. Editora: Centauro. São Paulo -SP. 2011.

MAGNANI, José Guilherme Cantor. De perto e de dentro: notas para uma etnografia urbana. Revista Brasileira de Ciências Sociais. vol. 17 n. 49, 2002. Disponível: https://www.scielo.br/scielo.php?pid=S010269092002000200002\&script=sci_abstract\&tlng= pt. Acesso em: 01 abr 2020.

MENDOZA, Edgar Salvador Gutiérrez. Sociologia da antropologia urbana no Brasil: a década de 70. Campinas: Universidade Estadual de Campinas, 2000.

SANTOS, Boaventura de Sousa. A cruel pedagogia do vírus. São Paulo: Boitempo, 2020.

SITE G1. Sem dados de SP, Brasil registra 897 mortes pelo novo coronavírus em 24 horas. Retirado de: https://g1.globo.com/bemestar/coronavirus/noticia/2020/07/28/casos-emortes-por-coronavirus-no-brasil-em-28-de-julho-segundo-consorcio-de-veiculos-deimprensa.ghtml. Acesso em: 28 jul. de 2020.

VELHO, Gilberto. (Org.); KUSCHNIR, Karina. (Org.). Pesquisas Urbanas: desafios do trabalho antropológico. 1. ed. Rio de Janeiro: Jorge Zahar Editor, 2003. v. 1. p.235.

VELHO, Otávio (org.). O fenômeno urbano. Rio de Janeiro, Zahar Editores, 1973. 